\title{
Rethinking Difference in the iWorld: Possibilities, Challenges and 'Unexpected Consequences' of Digital Tools in Literacy Education
}

\author{
LINDA LAIDLAW \\ University of Alberta \\ JOANNE O'MARA \\ Deakin University
}

\begin{abstract}
Within contemporary literacy classrooms, mobile touchscreen devices are occupying a more prominent place. For children who have disabilities or learning differences, such devices can offer increased participation and access and may also provide social capital to users. We share examples of how iPads and iPods were successfully used in classrooms by children who might be categorized as experiencing various challenges, as well as autobiographical examples we have experienced as parents of children with disabilities. Through these illustrations, we examine the possibilities of 'new tools' as well as challenges encountered in changing existing literacy practices.
\end{abstract}

Portable electronic touch screen devices such as the iPad and iPod are increasingly taking a place in aspects of contemporary childhood experiences including those of schooling (Kucirkova, Messer, Sheehy, \& Flewitt, 2013; O’Mara \& Laidlaw, 2011). It is important for students to develop abilities to utilize new technological tools and innovations in a rapidly changing world (Carrington \& Marsh, 2008; Knobel \& Lankshear, 2010; Lankshear \& Knobel, 2003a, 2003b; Merchant, 2007; Pahl \& Rowsell, 2012; Schleicher, 2012). These devices offer multimodal communication options, through digital video and audio-recording functions, accessibility features, multiple forms of text, and hundreds of different applications (apps). However, as Kucirkova, Messer, Sheehy, and Flewitt note (2013), these devices also bring together "a range of 'older' technologies, including audio-recorder, picture-camera, drawing pad and an on-screen keyboard" (p. 115) in one efficient tool.

Our ongoing research shows that these devices are more easily accessed by younger children than previous technologies, and elementary schools are taking up the usage of these devices very quickly, particularly in Australia (O'Mara \& Laidlaw, 2013), with Canada following closely behind in many jurisdictions. The affordances of touch screen devices offer young and preliterate children the possibility to independently design, create and produce their own texts in ways that are more easily facilitated than with tools such as paper and pencil (Flewitt, Messer, \& Kucirkova, 2014). We note that text composition and handwriting often become conflated at schools, both being termed "writing." Separating these skills enables young children to compose texts at their ability level, rather than being hindered by their still developing handwriting. For children who have disabilities or learning challenges, such tools can offer new opportunities and ease of access to and creation of text, particularly those for whom the physical burdens of 
handwriting present particular struggle. It is also important to note that with devices such as an iPad, it is still possible to learn 'handwriting' skills, using various apps, and to use printing or handwriting forms through the touch of a finger, which can provide further access for children who may struggle with holding a pencil. A variety of system accessibility options can help in situations where individuals have little fine motor control, using less precise gestures. Used this way, the device can also function as a digital paper (the screen) and pencil (a child's digit, hand, etc.), in ways that may be less burdensome for children with particular physical challenges.

As digital media theorists suggest, however, new digital tools invite both "hope and fear" (Gee \& Hayes, 2011, p. 4; Nixon \& Hateley, 2013), consistent with the emergence of 'new' literacy technology innovations across history. When these new tools are used for writing, there are often fears that handwriting skills will be abandoned and that changes in literacy teaching and learning practices will lead to decreased results in various standards of achievement-such discussions are frequently seen in newspaper articles and the popular media. Some researchers link more frequent use of digital technologies and cognitive tools to "[f] undamental changes in basic psychomotor and cognitive skills" (Sülzenbrück, Hegele, Rinkenauer, \& Heuer, 2011), suggesting that human repertoires are changing, with handwriting potentially an 'endangered' practice.

However, we note that literacy and its practices have continued to evolve and shift over time with the invention of, for example, alphabets, the printing press, and 'new' writing forms such as newspapers and novels. Plato's story in the dialogue Phaedrus provides evidence that the writing technologies and practices we now regard as necessary and which are woven across contemporary human experience were once viewed with suspicion; the invention of writing (and reading) was initially declared as creating forgetfulness and leading to the ruin of memory. Specific writing materials and tools have also evolved over time, shifting from use of many different tools (e.g. stone and clay tablets, papyrus, reed brushes, metal stylus) to more contemporary handwriting practice using a pencil or pen and paper, and now performed almost universally rather than limited to those in the role of scribes (Ong, 1982). This said, there is little doubt that new literacy technologies do have an impact on what human beings are capable of doing. We are all shifting and changing our own literary practices and we note continuing changes in our individual literacy habits. For instance, Jo is a calligrapher and was very proud of her highly practiced, artistic handwriting, adding flourishes to every piece of paper she wrote on, yet now almost never writes using a pen, handwriting only the occasional personal card and signing documents, and even these messages are often now sent as a personal email, or as a digital signature on her iPad. Both authors use laptops or touch screen devices (tablets or phones) for the vast majority of their daily writing, and we suspect that will also be true for many of our readers, who are also quite likely to be reading this issue online.

As Gleick (2011) suggests, information and literacy technologies have changed the nature of human consciousness, "The written word - the persistent word - was a prerequisite for conscious thought as we understand it" (p. 37). And it is likely, too, that digital literacy tools are similarly creating changes in human interaction and thought, provoking the sorts of responses we are witnessing, with contemporary writers addressing often polarized perspectives (see, e.g. Carr, 2010), and parents and teachers at times viewing 'new tools' with suspicion (Marsh, 2004), or teachers being unaware of the 
actual nature of children's digital practices in home environments (Arrow \& Finch, 2013; Honan, 2012). While there are some indications that attitudes towards digital writing tools and devices are changing, more recent studies still note areas of resistance (Neumann \& Neumann, 2014). From the opposite perspective, educational stakeholders can tend to promote the idea that new digital tools will solve all educational problems, or at least hold great promise, as we have seen in various digital literacy initiatives in education in both Canada and Australia (DEECD, 2014; Gov't of Alberta, 2012). Our position lies somewhere in the middle. Given historical changes that have emerged from 'new tools' over the ages (e.g. the alphabet, the printing press), we know that digital literacy tools are likely to have an impact on the literacy practices that are used in our own and our students' lives. However, we view the tools, however they may evolve, as providing further communication options, and, following Kress (2005, 2003) we understand digital tools having particular 'affordances.' Put simply, some tools are better for doing particular things than other tools might be, and some tools may afford different kinds of accessibility than other tools can do.

\section{Changing Literacy Practices at School}

Alongside the rapid emergence of digital media ${ }^{1}$, 'new' literacy forms and tools are becoming an increasing part of children's literacy experiences (see, e.g. Carrington, 2008; Marsh, 2004, 2006; Neumann \& Neumann, 2014). In relation to literacy practices at school, even the Organization for Economic Cooperation and Development's (OECD) Program for International Student Assessment (PISA) testing has begun to recognize the significance of digital literacy practice, through the inclusion of a digital reading assessment (OECD, 2011).

But even when the latest developments in digital technologies are introduced into the spaces of classrooms, practice may perpetuate approaches to teaching and learning based on $20^{\text {th }}$ century understandings. As parents, both of us have witnessed iPads and touch screen technologies taken up in both the Canadian and Australian elementary schools where our children attend, in addition to what we have observed in our research project. We have recently completed research within a Social Sciences and Humanities Research Council Insight Development Grant funded project, Literacy Learning in Playful Spaces: Using Multimodal Strategies to Develop Narrative with Young Learners, examining digital literacy tools and practices with young learners, investigating how iPads might be used in a kindergarten or early primary classroom setting as tools for developing literacy through the creation of stories and multimodal texts. As well, we are both parents of children who have experienced challenges relating to disabilities. While our children have different conditions (one of our children is missing fingers and has structural differences in both hands; one has Down Syndrome), both children have issues that impact writing ability in relation to pencil grip, although they are both skilled touch screen/iPad users and able readers who use such tools in ways that allow them to demonstrate a much higher level of competence than when they are struggling with a pencil.

Within both our roles as researchers working in a number of elementary schools and as parents of school-aged children, we have regularly observed some elements of

${ }^{1}$ Here, we are referring to 'media' as the plural of 'medium'.

Language and Literacy $\quad$ Volume 17, Issue 2, Special Issue 2015 Page 61


'fear' in relation to the use of new digital tools by children and in schools, also echoed by other researchers (Flewitt, Messer, \& Kucirkova, 2014). Further, we have noted that such 'fear' perspectives are frequently amplified in early literacy settings, somewhat surprisingly still consistent with Marsh's (2004) observations of teacher resistance to "the techno-literacy practices of young children" (p. 55), a decade ago. We have found the 'fear' or resistance perspectives are also at times applied to children who have learning differences or disabilities and for whom adaptive technologies simply 'level the playing field' of the classroom. We have observed that resistance to and problematization of the use of 'new literacy tools,' for accessibility or as adaptive devices, can arise around issues of 'sameness' and particular classroom 'standards': such concerns tend to be amplified in contexts where these sorts of devices are few, and expectations for 'uptake' are low. Curiously, we have heard comments from parents and teachers such as, "But it won't be fair to the rest of the class if Devon can use an iPad and the other children can't." Or, "QingQing needs to be doing what everyone else is doing - that's the aim of inclusion." Or, "Evan might stand out if he's using a tablet."

As others have suggested, the uses of mobile digital devices as "paradigm breakers" (Gov't of Alberta, 2011, p. 4) present challenges to beliefs about which skills and practices are of most value in the literacy classroom, and perhaps even - although we know this is a contentious stance-maintaining embedded beliefs about whose achievement might be of most value. Educational researcher Ben Whitburn, legally blind from early childhood, writes about such a "deficit discourse," referring to it as "the indelible ink of the special stamp" (p. 624, 2013a), noting that in his own educational experience, he was often more easily granted accommodations that would set him apart (e.g., use of a noisy Perkins Braille machine that disrupted others, so that he was then relegated to a corner of the classroom), or required him to be dependent on others- "on the hip of my minder" or "in mainstream with a chaperone," (2013b) - than adaptions that enabled "autonomous access to information" (p. 11), such as access to an electrical outlet for a computer. Heydon and Iannacci (2008) suggest that issues of 'normality' and 'abnormality' can often be used as colonizing forces in school environments, through the "lived literacy" curriculum and the discursive practices of schooling. Contemporary arguments made against the use of such tools in early primary classrooms are often, similarly, related to how such devices may disrupt existing hierarchies, or interfere with compliance (see, e.g. Rheingold, 2013). We also note that various school and district policies towards touch screen devices and assistive technologies create additional impacts on the "lived literacy" curriculum (Heydon \& Iannacci, 2008), aspects which we have both witnessed in our research contexts as well as experienced as parents. Concerns about control and ownership (i.e. the device cannot leave the classroom; apps may not be added without special consent) can create additional roadblocks - and in our observations, tend to be more common in classrooms and schools where devices are less familiar, and teachers less experienced with their use. Thus, the addition of new tools and devices into early literacy classrooms seem to bring together multiple intersections: the possibilities, affordances and limitations of various tools, attitudes towards adaption, discursive practices of schooling, and beliefs about 'what is essential' in literacy practice. We see this as an interesting location for further examination. 


\section{Methodological Framing and Context}

Both of us have worked collaboratively, within our project, looking at multimodal and digital practices in primary level classrooms (see, e.g., Laidlaw, O'Mara, \& Wong, in press; O'Mara \& Laidlaw, 2013). Over two years, Linda observed four Canadian early primary classrooms, examining ways that iPads and multimodal tools and practices could be used for storytelling, narrative and writing (Laidlaw \& O'Mara, with Makovichuk, 2013). Additionally, Jo has been a researcher in two Australian digital research projects with other colleagues (Beavis, O'Mara, \& McNeice, 2012a; Beavis, O'Mara, \& McNeice, $2012 \mathrm{~b}$ ), and including several months spent observing in preparatory level classrooms where students were working with iPads, in addition to visits to the Canadian primary sites. Within these projects, we have been able to observe digital practices and tools at a number of different levels, from the 'macro' observations of what was happening more generally in school contexts and different classrooms, to the 'micro' realms of individual children in our studies. Additionally, in the autobiographical realm, as parents we have observed our own children and their usage of digital devices in home and school environments. This mode of inquiry values working across levels, from the 'general' to the particularity of individual examples, located alongside one another in a larger research bricolage (Johnson, 2010; Lévi-Straus, 1966), piecing together smaller and larger-scale data and autobiographical examples in new ways, using complexity theory (Davis \& Sumara, 2010, 2008) as a methodological frame. Complexity enables us to look at broader patterns as a whole, noting that gaining an understanding of learning and social systems requires "considering all-at-once, the many layers of dynamic nested activity that are constantly at play" (Davis \& Sumara, 2006, p. 28).

For the purposes of this article, as a 'way in' to navigating the implications of 'new tools' for diverse learners in the iWorld (O'Mara \& Laidlaw, 2011) — we present a fictionalized 'snapshot' that draws on our multiple levels of data and our observations of how digital tools were sometimes approached in relation to issues of difference, disability and accessibility. Our use of this form is intentional, providing a form of a vignette, a structure that Linda has used elsewhere as a "narrative tableau" structure (Laidlaw, 2005, p. xvi). Within the theatre and in drama education, tableau is a dramatic form where participants freeze into place creating a 'still image' that others might view and interpret, similar to the 'statues' game children sometimes play. The tableau is a complex structure, and can be viewed, 'read' and interpreted in multiple ways, and provides a concrete yet abstract form for resymbolizing layers of meaning. We use this tableau structure to efficiently bring together multiple layers of meaning, and observations from our data and autobiographical experiences. We present this as a kind of provocation for response, in addition to its interpretive value.

It is also necessary to mention that while 'Emma' is a fictionalized compilation, the issues and examples are based on range of 'real' events that occurred, bringing together multiple events across different children, times and locations, into one description. 
Writing Difference in the iWorld: Emma

Emma:

Emma is in Grade One. Mostly she likes school, but she comes home frustrated on some days. Emma has missing fingers as well as other hand differences that impact her grip and she struggles to hold a pencil. She has many ideas and wants to express them, but if she must use a pencil, she is exhausted after printing anything more than a few words. Her printing also tends to be 'messy,' with some letters difficult to decipher. Her printing is not representative of her overall ability in language and literacy, and her physical disability is a permanent one, not remedied by any particular therapy. Emma works with several occupational therapists as well as a physical therapist, and after exploring a number of adaptive tools-pencil grips, a range of different writing implements, hand supports, with little improvement to her printing and much frustration-her therapists suggest that she begin to transition to using digital writing tools (an iPad or a laptop are suggested) for her writing at school. The OT informs Emma's mother, "The only thing she really needs to be able to do by hand is her signature." Emma is assessed by a local physical rehabilitation clinic to begin to use an iPad and a laptop for writing and representing at school.

When she uses these tools for her writing, Emma is able to share more complex ideas, a keen sense of humour, and her understanding of characters and plot. She is able to write longer passages without getting frustrated or tired. When she uses the iPad she often finds new ways to use apps that showcase her strengths as a problem-solver, and as a multimodal learner. She also explores her interests in new ways when she uses such tools at home, and becomes proficient at searching websites, apps and video collections, although at her school the Grade One children are not allowed Internet access on any of the mobile devices used in the classroom. Access is only allowed in the designated computer lab, where students mostly play math and spelling games and gameified typing programs that Emma is unable to use in any way that will benefit her keyboarding skills, as these programs are developed with normative hand structures in mind. Emma's teacher continues to emphasize the need for improving Emma's handwriting, even after the occupational therapist has emphatically stated that Emma's issue with her pencil grip is not something that any therapy will be able to remediate.

While her rehab team has recommended that Emma use an iPad for school writing and reading activities as much as possible, this advice is rarely taken up, even during class activities when very little or no additional lesson adaption would be needed, or when 'handwriting' could occur digitally through specific apps. Emma is never allowed to take the school iPad home due to school policy and liability issues, which means she does not have access to complete any writing she begins during the school day. Emma's report card, at the end of the school year, provides

${ }^{2}$ However, with the development of digital signatures, even this is becoming increasingly less necessary than it was in the past. 
assessments that seem to be based on what she is able to do with a pencil and paper and does not acknowledge the skills demonstrated when she uses electronic writing tools. Emma is positioned as a student who struggles, as someone who needs much support from an educational assistant. In contrast, Emma is completely independent in her use of her iPad, where she is knowledgeable about numerous 'productivity' apps. She tells her mother that she knows more about the iPad apps she uses than her teacher does....

In unpacking the preceding 'tableau'/snapshot/vignette, it is important to note that we have attempted to select an example that addresses a relatively uncomplicated aspect of literacy by focusing on 'handwriting', something that would be categorized as an “operational-technical" skill within Green's $(1988,2012)$ three dimensions of literacy. In our example, there seems little to be gained for Emma in pursuing traditional handwriting skills, more practice will not 'fix' her muscle issues, and, due to her physical differences, she is unlikely to be in the position where traditional handwriting development (with a pen or a pencil on paper) is achievable without a great deal of struggle. From our perspective, 'Emma' should be enabled to work on her strengths and her educational potential should be harnessed through her usage of digital media (typing, dictation, other sorts of digital writing apps) to record her thinking. With tools that increase accessibility, the lack of handwriting, and specifically 'pencil handling' skills should not hold her back in relation to her composition skills. While 'the loss of handwriting proficiency' is sometimes a topic of interest or intriguing debate in the media when digital alternatives are addressed-for example, the recent decision by Alberta Education to move to providing online options for provincial assessments, the trialing of final year of high school exams online in Victoria, Australia, and the elimination of handwriting from US core standards - and in other research examples (e.g. Sülzenbrück, Hegele, Rinkenauer, \& Heuer, 2011), new digital tools provide alternatives for children who might have difficulties in 'managing a pencil,' in addition to providing options for children who may use digital keyboarding or other kinds of writing skills rather than paper and pencil approaches out of preference.

We note that, as yet, there is very little research looking specifically at the use of mobile touch screen devices as writing and communication tools that addresses 'handwriting', although a number of researchers, writing from an occupational therapy perspective, have addressed keyboarding skills in comparison with handwriting skills. For example, in an examination of keyboarding in early education, Stevenson and Just (2014) state, "handwriting and keyboarding are not mutually exclusive," noting areas of overlap in relation to muscle control and coordination. They also suggest that, from an occupational therapy perspective, some children who experience difficulties with handwriting could be more competent in keyboarding, although they make the recommendation that, generally, children may gain more in letter recognition skills through beginning with handwriting rather than initially starting with keyboarding. However, there is little existing research on the impact of keyboarding on composition and writing skills (Connelly, Gee, \& Walsh, 2007).

Further, composition using a tablet can be quite different from computer keyboarding practices typically engaged for composition. While a child may be using some keyboarding skills on a tablet, these may be distinct from the keyboarding practices 
used in conjunction with 'traditional' keyboards or on computers, with a wide array of accessibility options. These may include 'assistive touch' functions which allow for adaptive 'gestures' to be used, connections to hearing aids, text adaption for visual difficulties, and 'speech to text' and dictation options. As well, children can create 'handwriting' forms, via touch (e.g. using the tip of a finger or other anatomy) through a range of applications, so that they may still be creating handwritten letter forms, minus the requirement to grasp a pencil. In both the Australian and Canadian classrooms where we have researched, we have seen various 'handwriting' apps used quite frequently as well as handwriting functions included as a part of various writing/book creation apps (e.g. Storykit, rED Writing, Scribblepress).

What we find troubling and curious in the 'Emma' vignette and the actual experiences (occurring across several children) that it is based upon, is our observation of both overt and more passive teacher or school resistance to using digital tools for the children who can clearly benefit. While educators would likely not suggest that a child who uses a prosthetic arm should remove it for physical education class to maintain 'fairness' and to properly maintain whatever assessment scheme is being used, digital literacy tools seem at times to be regarded differently, particularly where the 'new tools' are viewed as providing some further advantages to particular learners. When struggle with a pencil is presented as the best option to be pursued, almost as a moral imperative, we should be asking why that might be - and whether the difficulty perhaps resides in deeper educational assumptions, such as maintaining a 'disability discourse' (Whitburn, 2013a), or in fears about or allocation of scarce 'new tech' resources.

It may be that lack of experience with devices for teachers also complicates matters. In classrooms where all students have access to or ownership of tablets and teachers are expected to become familiar with a variety of applications, such as in Australian contexts where 'one-to-one' iPad initiatives are increasingly underway, or in contexts where teachers are focusing on innovative practices, we have observed interesting shifts and openness to 'how' things are written (e.g. a child being permitted to do his journal writing on his iPad rather than in a notebook; a teacher using multimodal apps for students to create classroom writing projects). We now present two research examples of innovative use of touch screen devices to support the development of emergent writing skills, as a counterpoint to the 'Emma' example, presenting these as part of the continuum of use to support difference and classroom diversity.

\section{Resistant Writer to Digital Film Producer: Lewis}

Within our classroom data, we gathered several examples where students who were categorized as 'at risk' in district early years evaluation structures and were not conventionally literate, were able to create a variety of texts that provided a scaffold to writing and more conventional literacy practices. We present one such vignette, a Kindergarten boy:

Lewis:

Lewis was resistant to participating in any writing or journal activities. Such tasks, when he was required to complete them, tended to include minimal detail and require much teacher support and encouragement. Lewis' writing in class tended to consist of a few shaky letters and sparse images, when he was required 
to write. Lewis was a child who was 'always moving' in the classroom-within photographs and video recordings he appears most often as a blonde-headed blur moving out of the camera frame. In a class project aimed at creating character studies, Lewis decided to video record his character as a way of sharing more about "Aidan the Dinosaur" using one of the class iPods. Within the series of 'movies' he created, Lewis set up his dinosaur's 'habitat' and activities and documented the life of his character in detail. He created typed text on the iPod, rehearsed and audio recorded spoken narrative and dialogue. Later, he worked with a student teacher on the classroom laptop to create titles for an edited movie version of his video to present to his classmates, sharing his final result with great pride.

In the example of 'Lewis', we see a child who has shifted from a position as 'struggling writer' to moving more fluidly between 'new tools' and 'old literacies' - working to create emergent writing and to begin to use his growing understandings of alphabetic principles in forming texts. Supported by his teacher to explore new modes of expression, and to follow his own interests in relation to choosing to work with an iPod instead of a pencil and his notebook, he was able to demonstrate his skills as an author and producer. For some children, the usage of the touch screen devices is enabling them to formally compose their own texts in ways which they previously could not access, or that involved more difficulty. While such children are more likely to also shift into eventually working with more traditional literacy tools and practices than children exemplified by the 'Emma' portrait, the provision of more accessible literacy tools and resources can play an important role in bridging what may be primarily developmental differences, providing multimodal options that may also be motivating due to enhanced student interest and ease.

Teaching Differently in the iWorld: Lisa

We would be remiss not to address the significance of the teacher in addressing innovative use of digital tools. Within the classrooms we have observed, in Canada and in Australia, we have seen teachers shifting their thinking about how to use touchscreen devices in relation to addressing classroom diversity and the individual needs of particular students, and also changing their mindsets about how the devices might be used to enhance literacy instruction for all students. We share the example of Lisa, an Australian early years primary teacher working in an inner city government school.

Lisa noticed that in her classroom, many of her students were experienced technology users who had much experience with touch screen devices (iPhones, iPods, iPads) since they were toddlers. Through the research project where she began working with Jo, Lisa started to consider ways in which she could incorporate iPads effectively within her overall literacy program. While originally she had focused on individual apps addressing particular learning outcomes, her thinking shifted to ways she might harness the range of affordances of the devices and their multimodal possibilities. 
Lisa began using some puppet apps, which enabled students to record their spoken language and to create a movie of puppets acting out particular scenes. Lisa noticed that when students were using these apps, students were able to write more sophisticated responses to the tasks she was setting, as they did not have to rely entirely on handwriting/printing or drawing pictures to communicate their ideas and their capabilities were expanded. After initial exploration with these tools, Lisa designed a series of "writing as composition" activities that capitalized on the affordances of the digital tools, using the voice recording tools. Students created text responses, using the puppet app, gave their opinions on issues by using the movie camera to make short films, and recorded their own reading and listened back to it.

In conversation with Jo, Lisa stated that she had always used the word 'writing' for handwriting and composing, but that the composition of text is often hindered by lack of handwriting/basic skills for early literacy learners:

"I was so pleased with the work they did-it was so much better than what they could do when they were constrained to paper and pen."

As Lisa uncovered in her explorations with students using touch screen devices, the options that were provided enabled young children to develop composition skills in more depth than their handwriting/typing/decoding skills would typically allow, had they used the tools of paper and pencils or crayons. This means that the skills of composition and 'getting the words down' could be developed together, with purposeful ideas and more sophisticated communication forms not lost by the limitations of early or emergent writing skill. While Lisa used these multimodal strategies for all her students and they offered an accessible way to create various texts for all early writers, they were of particular benefit to students who had specific areas of difficulty, as English language learners, and for children who struggled more than their peers in terms of writing or alphabetic understanding.

\section{Rethinking Possibilities}

The affordances of digital tools, in enabling use of sound/speech control, gestural operations that provide options for variations in fine motor control, and different forms of representation, present possibilities that are now being explored in primary classrooms across both Canada and Australia. However, as we have noted in our own research contexts, such practices tend to be regarded, at least initially, as less important in relation to the handwriting practices and skills that have been traditionally valued in early literacy classrooms. In Victoria, Australia, Jo is observing a high level of adoption of iPads in elementary schools, including many 'one-to-one' school initiatives where children begin in their preparatory year with an iPad as an essential part of 'school supplies'. In such settings, often parents in particular are worried about the loss of handwriting skills, even though handwriting is a compulsory part of the Victorian state curriculum that teachers are still addressing (although now sometimes using a handwriting 'app', for example, Australian Touch and Write: Victorian Cursive). Fewer school districts in Canada have one-to-one iPad or tablet implementation, although we note some ongoing shifts in that 
regard. However, frequent Canadian educational news stories lament the decline of handwriting instruction (see for example, CTV News, 2013; Penhorwood, 2012). We are watching with interest, and expect to see further public response in a similar fashion once tablet use becomes even more established in Canadian elementary schools.

Even in situations where teachers are exploring innovative use of digital tools, such as within our research classrooms, the worry about 'next year' is often present, because time spent on exploring, creating, and producing digital texts translates into less time spent on learning how to neatly print the alphabet. And that surface detail - the 'how you write it'-becomes important even for the children who, for reasons relating to specific disabilities or challenges, will never be able to master printing without sacrificing more significant literacy aims such as conveying meaning, flow of ideas and critical thinking within composition. As our example of Lisa presents, shifts in the digital realm are inviting and provoking shifts in thinking about literacy practice for teachers, and perhaps will lead to eventual changes in what literacy educators understand as necessary or important as basic 'early literacy skills.'

As our title suggests, we have been rethinking notions of 'difference' and noting that new tools are shifting possibilities for some children, who otherwise may be disadvantaged in relation to 'getting their words down,' to be able to participate more fully in their classrooms. We observe that educators are taking up touch screen devices and seeing new affordances for learners, particularly within the innovative examples we see continuing to emerge in the teachers we work alongside. Our examples, at the level of inclusion, at the level of providing options for students working outside of 'normative' skill expectations and within the realm of how teachers might take up new tools, also suggest a need for further consideration in relation to literacy instruction, with the advent of new tools and practices that significantly shift the way that text creation can take place and be produced. In an era that has tended to valourize formal and high-stakes assessment practices, teachers may also be struggling with how to incorporate new tools and approaches, and yet still address district, province/state or national (in the case of Australia) mandates in relation to required skills and educational 'standards.' But we also wonder about the resilience of what have often been traditional hierarchies around learning and learners, and ideas around which skills are still most valued, both for individual children and in relation to literacy curriculum. We conclude with some questions, the ones that sometimes keep us up at night in connection to our own children, and that we continue to ask of teachers in our ongoing digital research projects:

Does it really matter if not all children learn how to use a pencil properly, but instead use digital forms of writing? (Will civilization as we know it go to ruin, as was suggested with the invention of writing in the era of Plato?)

When the elementary-aged students we know now are completing their final year of high school exams online (or in Alberta, all provincial achievement testing...), will efforts spent teaching handwriting in the early years be seen as 'a waste'?

Are there concerns more specific to handwriting forms (e.g. learning letters more effectively, through handwriting) that can still be addressed using touchscreen digital devices to learn letter formation? Or is some of the resistance just 'all about using electronic devices'? 
We conclude with what is our burning question, and one we continue to ponder: What will it take for education to 'rethink difference' in relation to the affordances of new literacy tools and practices?

We are hopeful about the emergence of future possibilities and options.

\section{Acknowledgements}

The authors acknowledge the Social Sciences and Humanities Research Council of Canada for their support of the research described in this article, and in the project, Literacy learning in playful spaces: Using multimodal strategies to develop narrative with young learners.

\section{References}

Arrow, A. W., \& Finch, B. T. (2013). Multimedia literacy practices in beginning classrooms and at home: The differences in practices and beliefs. Literacy, 47(3), 131-141. doi: 10.1111/lit.12006

Beavis, C., O’Mara, J., \& McNeice, L. (2012a). Digital games: Literacy in action. Adelaide, Australia: Wakefield Press.

Beavis, C., O’Mara, J. \& McNeice, L. (Eds.). (2012b). Literacy learning from computer games. Adelaide, Australia: Wakefield Press/The Australian Association for the Teaching of English.

Carr, N. (2010). What the Internet is doing to our brains: The shallows. New York: W.W. Norton.

Carrington, V. (2008). “I'm Dylan and I'm not going to say my last name”: Some thoughts on childhood, text and new technologies. British Educational Research Journal, 34(2). doi: 10.1080/01411920701492027

Carrington, V., \& Marsh, J. (2008). Forms of literacy. Beyond Current Horizons Challenge Paper. Retrieved from http://www.beyondcurrenthorizons.org.uk/forms-of-literacy/

Cort, D. (2013). Australian Touch and Write: Victorian Cursive. (Version 2.0). [Mobile application software]. Retrieved from http://itunes.apple.com

CTV News. (2013). Is it time to stop teaching cursive handwriting? CTV News. Retrieved from: http://www.ctvnews.ca/canada/is-it-time-to-stop-teachingcursive-handwriting-1.1147200

Connelly, V., Gee, D., \& Walsh, E. (2007). A comparison of keyboarded and handwritten compositions and the relationship with transcription speeds. British Journal of Educational Psychology, 77, 479-492.

Davis, B., \& Sumara, D. (2010). 'If things were simple...': complexity in education. Journal of Evaluation in Clinical Practice, 16, 856 - 860. doi: 10.1111/j.13652753.2010.01499.x

Davis, B., \& Sumara, D. (2008). Complexity as a theory of education. Transnational Curriculum Inquiry, 5(2) Retrieved from http://nitinat.library.ubc.ca/ojs/index.php/tci 
Davis, B., \& Sumara, D. (2006). Complexity and education. Mahwah, NJ: Lawrence Erlbaum.

Department of Education and Early Childhood Development, Victoria. (2014). Planning for 1-to-1 learning: Ensure teachers are confident and capable in using 1-to-1 devices in their teaching practice. Victoria, Australia: Digipubs. Retrieved from https://fuse.education.vic.gov.au/digipubs/Sustaining\%20a\%201 to 1\%20Program $\% 20 \mathrm{in} \% 20 \mathrm{a} \% 20$ School/Ensure $\% 20$ teachers $\% 20$ are $\% 20$ confident $\% 20$ and $\% 20$ cap able $\% 20$ in $\% 20$ using $\% 201$-to1\%20devices\%20in\%20their $\% 20$ teaching\%20practice.aspx

Flewitt, R., Messer, D., \& Kucirkova, N. (2014). New directions for early literacy in a digital age: The iPad. Journal of Early Childhood Literacy. doi: $10.1177 / 1468798414533560$

Gee, J., \& Hayes, E. (2011). Language and learning in the digital age. New York: Routledge.

Gleick, J. (2011). The information: A history, a theory, a flood. New York, NY: Pantheon Books.

Government of Alberta. (2011). iPads: What are we learning? Summary report of provincial data gathering day, October 3, 2011. Retrieved from http://education.alberta.ca/admin/technology/research.aspx

Heydon, R., \& Iannacci, L. (2008). Early childhood curricula and the de-pathologizing of childhood. Toronto, ON: University of Toronto Press.

Honan, E. (2012). 'A whole new literacy': Teachers understanding of students' digital learning at home. Australian Journal of Language and Literacy, 35(1), 82-98.

Green, B. (1988). Subject- specific literacy and school learning: A focus on writing. Australian Journal of Education, 32(2), 156-179.

Green, B. (2012). Subject specific literacy, writing and school learning: A revised account. In B. Green \& C. Beavis, (Eds.), Literacy in 3D: An integrated perspective in theory and practice. Australian Council of Educational Research Press: Melbourne.

Johnson, S. (2010). Where good ideas come from: The natural history of innovation. New York: Riverhead Books.

Kucirkova, N., Messer, D., Sheehy, K., \& Flewitt, R. (2013). Sharing personalised stories on iPads: A close look at one parent-child interaction. Literacy - UKLA, 47(3), 115-122.

Knobel, M., \& Lankshear, C. Eds. (2010). DIY media: Creating, sharing and learning with new technologies. New York: Peter Lang.

Kress, G. (2005). Communication now and in the future. Discussion paper for the English 21 Project: United Kingdom Qualifications and Curriculum Authority. Retrieved from http://www.qca.org.uk/12292html

Kress, G. (2003) Literacy in the new media age. London: Routledge.

Laidlaw, L. (2005). Reinventing curriculum: A complex perspective on literacy and writing. Mahwah, NJ: Lawrence Erlbaum.

Laidlaw, L., \& O'Mara, J. with Makovichuk, L. (2013). With rest and time and a little hope: Moving into virtual worlds through multi-modal literacy forms. In A. Goodwyn, L. Reid \& C. Durrant (Eds.), International perspectives on teaching English in a globalized world. London, UK: Routledge. 
Laidlaw, L., O’Mara. J., \& Wong, S. (2015). "Daddy, look at the video I made on my iPad!": Reconceptualizing 'readiness' in the digital age. In J. Iorio \& W. Parnell (Eds.), Early childhood education: Implications for policy and practice. New York: Palgrave.

Lankshear, C., \& Knobel, M. (2003a). New literacies: Changing knowledge and classroom learning. Philadelphia, PA: Open University Press.

Lankshear, C., \& Knobel, M. (2003b). New technologies in early childhood literacy research: A review of research. Journal of Early Childhood Literacy 3, 59-82.

Lévis-Strauss, C. (1966). The savage mind. (2 ${ }^{\text {nd }}$ ed.) Chicago: University of Chicago Press.

Luke, A., \& Freebody, P. (1999). Further notes on the four resources model. Reading Online - Research. Retrieved from http://www.readingonline.org/research/lukefreebody.html

Marsh, J. (2006). Global, local/public, private: Young children's engagement in digital literacy practices in the home. In K. Pahl \& J. Rowsell (Eds.), Travel notes from the New Literacy Studies (pp. 19-38). Clevedon, England: Multilingual Matters.

Marsh, J. (2004). The techno-literacy practices of young children. Journal of Early Childhood Research 2(1), 51-66.

Merchant, G. (2007, November). Writing the future in the digital age. Literacy, UKLA 41(3), 118-128.

Neumann, M., \& Neumann, D. (2014). Touch screen tablets and emergent literacy. Early Childhood Education Journal, 42(4), 231-239. doi: 10.1007/s10643-013-0608-3

Nixon, H., \& Hateley, E. (2013). Books, toys and tablets: Playing and learning in the age of digital media. In K. Hall, T. Cremin, B. Comber \& L. Moll (Eds.), International handbook of research into children's literacy, learning and culture. London: Wiley-Blackwell.

OECD. (2011). PISA 2009 results: Students on line: Digital technologies and performance (vol. VI). Retrieved from http://dx.doi.org/10.1787/9789264112995en

O'Mara, J., \& Laidlaw, L. (2011) Living in the iWorld: Two researchers reflect on the changing texts and literacy practices of childhood. English Teaching: Practice and Critique 10(4), 149-159. Retrieved from http:/education.waikato.ac.nz/research/files/etpc/files/2011v10n4nar2.pdf

O’Mara, J., \& Laidlaw, L. (2013, December). Teaching in the iWorld: Developing a repertoire of pedagogical discourse around the usage of touch-screen devices in early childhood classrooms. Paper presented at the Australian Association for Research in Education, Shaping Australian Educational Research, Adelaide 1-5 December, 2013.

Ong, W. (1982). Orality and literacy: The technologizing of the world. London: Routledge.

Pahl, K., \& Rowsell, J. (2012). Literacy and education (2nd ed.). Los Angeles, CA: SAGE.

Penhorwood, C. (2012). Does handwriting have a place in today's tech-driven classrooms? CBC News, April 29, 2012. Retrieved from http://www.cbc.ca/news/canada/does-handwriting-have-a-place-in-today-s-techdriven-classrooms-1.1231769 
Plato. (1961). The collected dialogues of Plato. E. Hamilton \& H. Cairns (Eds.), Lane Cooper, trans. Princeton, NJ: Princeton University Press.

Rheingold, H. (2013). Q \& A: Howard Reingold on using technology to take learning into our own hands. Interview in Spotlight on Digital Media and Learning (Blog), May 14, 2013. Retrieved from: http://spotlight.macfound.org/featuredstories/entry/qa-howard-rheingold-on-using-technology-to-take-learning-into-ourown-hands/

Rogue Mobile. (2012). rED Writing: Learn to Write. (Version 1.2.1). [Mobile application software]. Retrieved from http://itunes.apple.com

Schleicher, A. (2012). Learning in the $21^{\text {st }}$ century: Policy lessons from around the world. OECD. Presentation to the British Columbia School Superintendents Association (BCSSA), November 15, 2012, Vancouver, BC. Retrieved from http://prezi.com/x7zrlsmaehfv/teachers-in-the-21st-century/

Scribble Press Inc. (2014). Scribble Press. (Version 2.0.5). [Mobile application software]. Retrieved from http://itunes.apple.com

Stevenson, N. C., \& Just, C. (2014). In early education, why teach handwriting before keyboarding? Early Childhood Education Journal, 42(1), 49-56. doi:10.1007/s10643-012-0565-2

Sülzenbrück, S., Hegele, M., Rinkenauer, G., \& Heuer, H. (2011). The Death of Handwriting: Secondary Effects of Frequent Computer Use on Basic Motor Skills. Journal of Motor Behavior, 43(3), 247-251. doi:

10.1080/00222895.2011.571727

University of Maryland. (2012). Storykit. (Version 1.1) [Mobile application software]. Retrieved from http://itunes.apple.com

Whitburn, B. (2013a). The indelible ink of the special stamp: An insider's research essay on imprints and erasures. Disability \& Society, doi:

10.1080/09687599.2013.844097

Whitburn, B. (2013b). The dissection of paraprofessional support in inclusive education: 'You're in mainstream with a chaperone.' Australasian Journal of Special Education. Advanced online publication. doi:10.1017/jse.2013.12.

\section{Author Biographies}

Dr. Linda Laidlaw is an associate professor in early literacy education at the University of Alberta, Edmonton, Alberta, Canada. She works as a literacy researcher and teaches courses in undergraduate and graduate language and literacy education and curriculum studies. Her current research focuses on digital literacies and multimodal practice for young learners, and follows from earlier projects investigating family diversity in relation to contemporary classrooms. In collaboration with Joanne O'Mara she has been engaged in several Social Sciences and Humanities Research Council of Canada (SSHRC) funded research projects, exploring the use of mobile touch screen devices and other digital tools within early primary literacy instruction as a means to facilitate the creation, modification and use of children's own multimodal texts, within work in drama and early literacy. 
Joanne O'Mara is a language and literacy researcher and teacher at Deakin University, Melbourne, Australia. Her research program centres on the investigation of innovative pedagogy and practices and the spatial and temporal dimensions of teachers' work. She has a particular interest in the areas of digital literacies and the arts. She is passionate about her ongoing series of research projects in the areas of drama education pedagogy and practices, digital games, emergent literacies and new textual practices. Together with Linda Laidlaw, she has been researching young children's literacy practices. Working with early years classrooms, they have been developing pedagogical approaches that combine drama and new technologies, drawing on the skills that these young children bring with them as they enter school. 